borderline IQ Development was normal in 2 of 3 patients without neuroblastoma and in only 1 of 8 whose opsoclonus-myoclonus was associated with neuroblastoma. (Hammer MS, Larsen MB, Stack CV. Outcome of children with opsoclonus-myoclonus regardless of etiology. Pediatr Neurol July 1995;13:21-24). (Respond: Dr Hammer, Division of Pediatric Neurology, Children's Memorial Hospital, 2300 Children's Plaza, \#51, Chicago, IL 60614).

COMMENT. Other terms for this syndrome include myoclonic encephalopathy of infancy (MEI), dancing eyes syndrome, and infantile polymyoclonia. The majority of children with opsoclonusmyoclonus in this study were found to have significant developmental delay. Others report that about $50 \%$ are left with intellectual deficits. (Boltshauser E et al. Helv Pediatr Acta 1979;34:119). The criteria for diagnosis were 1) marked motor incapacity from myoclonic jerking and/or cerebellar ataxia, 2) opsoclonus, 3) acute or subacute onset, and 4) absence of central nervous system infection. All 3 children with MEI without neuroblastoma had a viral illness 1-2 weeks before symptoms began. The pathogenesis is multiple and is usually viral in origin, notably poliovirus, Coxsackie virus B3, and St Louis encephalitis virus. An autoimmune mechanism and DDT intoxication have also been invoked. (Menkes JH. Textbook of Child Neurology. 3rd ed. Philadelphia, Lea \& Febiger, 1985). In treatment, some advocate ACTH for the acute stage followed by predisone for several months. (see Progress in Pediatric Neurology I, 1991, Chicago, PNB Publishers, p 486).

\title{
HIV INFECTION AND NEURODEVELOPMENT
}

The mental and motor development of 24 children with vertically transmitted human immunodeficiency virus (HIV) infection in the first 30 months of life was compared to 27 HIV exposed but uninfected children at the Boston City Hospital and Boston University Medical Center, MA. Bayley Scales of Infant Development, assessed at 4-16 months and at 17-30 months of age, showed that motor development in the infected group was delayed compared to the uninfected seroreverter group in both age periods. Mental development was similar in the two groups at 4-17 months, but was delayed in the HIV infected children at 17-30 months of age. (Chase C et al. Early neurodevelopmental growth in children with vertically transmitted human immunodeficiency virus infection. Arch Pediatr Adolesc Med August 1995;149:850-855). (Reprints: Dr Chase, Department of Pediatrics, D4S, Boston City Hospital, 818 Harrison Ave, Boston, MA 02118).

COMMENT. Neurodevelopmental outcome in children with HIV infection is variable, but early delay in motor development and late infantile deceleration in mental development can be expected in HIV infected children.

\section{TOXIC DISORDERS}

\section{LEAD EXPOSURE IN DAY CARE CENTERS}

The risk of lead poisoning among 155 of 234 eligible children (mean age, 4.8 years) enrolled in university affiliated day care centers with elevated environmental lead sources was determined at the Department of Pediatrics and University Hygienic Laboratory, The University of Iowa, Iowa City. 
Elevated levels of lead in paint $(2.4 \%$ - $40 \%$ lead) were found in all six centers tested. Three centers were found to have elevated lead levels in windowsill dust (62000-180000 g Pb/sqM) or soil (530-1100 mg Pb/kgm). Questionnaires completed by parents showed low risk of lead exposure in the homes. Blood lead levels were less than $10 \mathrm{mcg} / \mathrm{dL}$ in all but one child. (Weismann DN et al. Elevated environmental lead levels in a day care setting. Arch Pediatr Adolesc Med August 1995;149:878-881). (Respond: Dr Weismann, Department of Pediatrics, University of Iowa Hospitals and Clinics, 200 Hawkins Dr, Iowa City, IA 52242).

COMMENT. The lead-safe home environment, careful supervision, and good personal hygiene of these children would explain the relatively low blood lead levels despite elevated environmental lead levels in the day care centers. Major, costly lead abatement efforts would have been unwarranted in this situation.

Pediatric neurologists evaluating children with ADHD are cognizant of the role of lead exposure in the etiology of learning and behavior problems. The home and play environment questionnaire is important in determining the need for blood lead level determinations. Treatment guidelines for lead exposure in children are outlined in an American Academy of Pediatrics Committee on Drugs report. (Berlin CM Jr et al. Pediatrics July 1995;96:155-160). Chelation therapy is indicated in patients with blood lead levels of $45 \mathrm{mcg} / \mathrm{dL}$ and above, and sometimes in those with persistent levels of $25-45 \mathrm{mcg} / \mathrm{dL}$, despite environmental abatement. Chelation is not indicated for levels less than $25 \mathrm{mcg} / \mathrm{dL}$.

\section{ATTENTION DEFICIT DISORDERS}

\section{RESPONSE PREDICTION TO METHYLPHENIDATE IN ADHD}

The pattern of individual responses to methylphenidate $(10 \mathrm{mg})$ and factors that predict drug response in 46 children, 6-13 years old, with attention-deficit hyperactivity disorder (ADHD) were examined at the Department of Child and Adolescent Psychiatry, and the Rudolf Magnus Institute for Neurosciences, University of Utrecht, The Netherlands. Methylphenidate (MPH) normalized school behavior in one half the subjects, and behavior at home in one third. Behavior both at school and at home was normalized in $17 \%$. Prediction of response to MPH was only successful when stringent, ie cross-situational, response definitions were used. Predictors were a high IQ much inattentiveness, young age, low severity of disorder, and low rates of anxiety. Positive behavioral changes, measured by the Abbreviated Conners Rating Scales, after a single dose of MPH were predictive of crosssituational improvement after 4 weeks of MPH treatment. (Buitelaar JK et al. Prediction of clinical response to methylphenidate in children with attentiondeficit hyperactivity disorder. L Am Acad Child Adolesc Psychiatry August 1995;34:1025-1032). (Reprints: Dr Buitelaar, Department of Child Psychiatry, PO Box 85500, 3508 GA Utrecht, The Netherlands).

COMMENT. The clinical judgment of severity of ADHD and improvement observed after a single dose of methylphenidate are useful predictors of a beneficial long-term response.

The importance of a multimodal treatment approach to ADHD is emphasized by The National Institute of Mental Health's recently initiated 5-year, multisite study. Questions to be answered 